\title{
The relationship between pain intensity, pain-related suffering, and the patient satisfaction level before and after treatment in patients with musculoskeletal disorders: A pilot study
}

\author{
Katsuyoshi Tanaka1) Tomohiko Nishigami2) Akihisa Watanabe ${ }^{3)}$ \\ Akira Mibu1) Hirobumi Kawamura ${ }^{2)}$ Masahiro Utsumi ${ }^{3)}$ Koji Hattori $^{2)}$ \\ 1) Department of Rehabilitation, Tanabe Orthopedic Clinic \\ 5-52, Tennouji-ku, Osaka, Osaka, Japan, 543-0027 \\ Tel: +81-6-6774-1151, Fax: +81-6-6774-1152 \\ 2) Department of Nursing and Physical Therapy, Konan Woman's University \\ 3) Department of Rehabilitation, Utsumi Orthopedic Clinic
}

JAHS 7 (2): 22-29, 2016. Submitted Jan. 18, 2016. Accepted Mar. 31, 2016.

\begin{abstract}
:
PURPOSE: Pain intensity, suffering, patient's satisfaction level may be considered as important part of multidimensional assessment. The first aim of the present study was to examine whether there were differences in the rate of improvement in pain intensity and pain-related suffering before and after treatment in patients with musculoskeletal disorders. The second aim was to investigate correlations between the patient satisfaction level, pain intensity, and pain-related suffering before and after treatment. METHODS: Forty-four participants were recruited. Pain intensity, pain-related suffering, and patient satisfaction level were assessed before and after treatment for 6 weeks. RESULTS: Significant difference was observed in pain intensity and pain-related suffering after treatment. The rate of improvement in pain-related suffering was significantly higher than that in pain intensity. Multiple linear regression analysis showed that only pain intensity before treatment was related to the patient satisfaction level before treatment and only the rate of improvement in pain-related suffering was related to the patient satisfaction level after treatment. CONCLUSION: The interesting finding of this study was that the primary factor for patient satisfaction level changed from pain intensity to the rate of improvement in pain-related suffering. These results may give important information to determine a treatment policy.
\end{abstract}

Key words: Pain intensity, Patient satisfaction, Suffering 


\section{INTRODUCTION}

Musculoskeletal disorders are highly prevalent in the general population worldwide ${ }^{1-3)}$. The most common musculoskeletal pain problems affect the lower back, shoulder, neck, and $\mathrm{knee}^{4)}$. Although pain is a common problem in musculoskeletal disorders, it is difficult to assess because there are no objective biological markers for the presence of pain. Pain is composed of not only sensory-discriminative aspects but also emotional, cognitive, motivational, and affective components. Multidimensional assessment is needed because perceived pain and disability differ considerably between individuals with similar pain conditions.

Pain intensity may be defined as the degree of pain severity reported by an individual and is used most frequently in pain assessment. Besides pain intensity, suffering may be considered as important part of a multidimensional assessment. Some authors suggest that pain differs from suffering. Chapman et al. ${ }^{5}$ stated that suffering is a broader state that encompasses more dimensions than pain and has many potential causes, of which pain is only one. Turk et al. ${ }^{6)}$ asserted that pain and suffering may be interdependent and have a reciprocal and synergistic relationship. Furthermore, Loeser ${ }^{7)}$ proposed a concept consisting of nociception, pain, suffering, and pain behavior and suggested that suffering reflects a threat to the integrity of the individual. Suffering is understood to consist of an emotional experience involving a complex interaction between physical, cognitive, affective, and spiritual components ${ }^{8-10}$. Thus, it is important to divide and evaluate pain intensity and pain-related suffering. The Verbal Rating Scale ${ }^{11)}$ and Pain Discomfort Scale ${ }^{12)}$ are used to assess pain-related suffering. There have been no reports that evaluate pain intensity and pain-related suffering simultaneously using the Numeric Rating Scale (NRS) before and after treatments. NRS may be preferred for the assessment of pain intensity in the clinic because of its ease of use and standardized format. Clinicians may be able to use it when deciding on an appropriate treatment policy by determining the change in pain intensity and pain-related suffering.

Recently, a patient's satisfaction with his or her current status is increasingly being considered as an important outcome of medical interventions. The Visual Analog Scale (VAS) ${ }^{13,14)}$ and Likert scale ${ }^{15,16)}$ are used to evaluate the patient satisfaction level. Although several studies ${ }^{16-20)}$ have investigated the relationship between the patient satisfaction level and pain intensity, it not yet known whether the patient satisfaction level is related to pain-related suffering. We hypothesize that pain-related suffering is also related to the patient satisfaction level because patient satisfaction is a concept including affective aspect, degree of disability, and quality of life. In rehabilitation practice, since the patient satisfaction seems to be of importance for the musculoskeletal disorders situation, it was considered important to examine whether the patient satisfaction was related with pain intensity and pain-related suffering in these patients.

The first aim of the present study was to examine whether there were differences in the rate of improvement in pain intensity and pain-related suffering before and after treatment. The second aim was to investigate correlations between the patient satisfaction level, pain intensity, and pain-related suffering before and after treatment.

\section{MATERIALS AND METHOD}

Study participants and protocol.

Patients with musculoskeletal disorders were recruited consecutively within the orthopedics clinic. All male and female patients (age, 30-80 years) with musculoskeletal pain of at least 1-month duration affecting the lower back or limbs were eligible for inclusion. The exclusion criteria were serious pathologies (unhealed fractures, tumors, acute trauma, or serious illness), neurological findings (muscle weakness, loss of sensibility, or reflexes), and severe psychiatric disorders. No participant had a history of visiting psychosomatic medicine or pain clinic, and no physiotherapy could have been received prior to this study at least three months.

Ethical approval was obtained from the institutional ethics committee of Konan Women's university. Written informed consent was obtained from all participants prior to the study. The study was 
conducted in compliance with the Declaration of Helsinki.

Pain intensity, pain-related suffering, and patient satisfaction level were assessed before and after treatment. The mean intensity and suffering that arose from pain during the last week were rated from 0 to 10 $(0=$ no pain/suffering at all; $10=$ unbearable pain/suffering) using NRS. The difference in pain intensity and pain-related suffering was calculated by subtracting pain-related suffering from pain intensity before and after treatment. Patients with musculoskeletal disorders were divided into the following subgroups according to their differences in the values before and after treatment: Zero (pain intensity = pain-related suffering), Plus (pain intensity $>$ pain-related suffering), and Minus (pain intensity $<$ pain-related suffering). The rate of improvement in pain intensity and pain-related suffering was calculated using the following formula: (before treatment - after treatment)/before treatment. To assess a participant's level of satisfaction with their current state (including daily life, pain level, and functional impairment), the patients were asked to rate their satisfaction level by VAS from 0 to $100(0=$ most satisfied; $100=$ least satisfied), according to methods described by Singer et $\mathrm{al}^{13)}$.

Treatment included medication, physical therapy, and patient education. Non-steroidal anti-inflammatory drugs (NSAIDs) were administered as a single dose. The participants were required to attend three times a week for 6 weeks. All physical therapists with an average of 7 years' working experience and an experience in the management of patients with musculoskeletal conditions prior to involvement in the trial were considered eligible to provide treatment to the participants. Physical therapy included exercise (muscle training and muscle stretching) and manual therapies (joint mobilization or manipulation techniques applied to the spine or joint consistent with best current manual therapy practice) according to each musculoskeletal disorder. The exercises were performed under the supervision of a physical therapist. The participants received 20-minutes physical therapy two to three times a week. The main aims of the program were to decrease pain and improve physical function and disability. The intensity of the exercises progressed over the treatment period, with the participants being encouraged to improve their own performance. Each session lasted $20 \mathrm{~min}$ and included a short period of manual therapy. Home exercises were taught and the ability to perform them was assessed at each treatment session. The participants were instructed to perform home exercises four times a week. All participants received education regarding posture and body mechanics involved in activities of daily living and education on pain neuroscience. They were instructed on the preferred positioning of the trunk, shoulder, and lower limbs during daily activities and work according to each musculoskeletal disorder. The participants were also educated about the neurobiology and neurophysiology of pain and pain processing by the nervous system.

Statistical analysis

Statistical analysis was performed using SPSS software version 22.0J (IBM, New York, NY). The difference between pain intensity and pain-related suffering before and after treatment, the difference in pain intensity, pain-related suffering, and the patient satisfaction level before treatment and after treatment, and the difference in the rate of improvement in pain intensity and pain-related suffering were compared using the paired $t$ test. The number of participants was compared between the Zero, Plus, and Minus subgroups using the chi-square test.

A multiple linear regression analysis was performed to define the contribution of independent variables (age, pain duration, pain intensity, pain-related suffering before and after treatment, and rate of improvement in pain intensity and pain-related suffering) to the dependent variable (patient satisfaction level before and after treatment). The significance level was set at $\mathrm{p} \leq 0.05$.

A sample size calculation for the paired t test, the chi-square test and the multiple linear regression analysis was conducted with $\mathrm{G}$ *Power 3.1 (University of Kiel, Germany) with an large effect size of Cohen, significance $\alpha$ $=0.05$, and an expected power of $(1-\beta)=0.8$. This yielded a sample size of $\mathrm{n}=15$ in the 
paired t test, 39 in the chi-square test and 43 in the multiple linear regression analysis that was determined through a 2 -tailed distribution calculation. Post hoc power analyses were conducted for the paired t test, the chi-square test and the multiple linear regression. Powers were 0.99 in pain intensity (paired t test, Pre vs. Post), 0.99 in suffering intensity (paired t test,
Pre vs. Post), 0.99 in patient satisfaction (paired t test, Pre vs. Post), 0.73 in the rate of improvement (paired t test, Pain vs. suffering), 0.87 in the chi-square test, 0.96 in the multiple linear regression analysis in the patient satisfaction level before treatment and 0.94 in the multiple linear regression analysis in the patient satisfaction level after treatment.

Table1. Distribution of participants regarding musculoskeletal pain according to age, sex and clinical profile.

\begin{tabular}{ccccc}
\hline & $\begin{array}{c}\text { Total } \\
(\mathrm{n}=44)\end{array}$ & $\begin{array}{c}\text { Shoulder pain } \\
(\mathrm{n}=25)\end{array}$ & $\begin{array}{c}\text { Low back pain } \\
(\mathrm{n}=13)\end{array}$ & Knee osteoarthritis $(\mathrm{n}=6)$ \\
\hline $\begin{array}{c}\text { Age (years) } \\
\text { Female sex }\end{array}$ & $64.0 \pm 10.9$ & $64.2 \pm 11.7$ & $63.2 \pm 8.0$ & 7 \\
$\begin{array}{c}\text { Pain intensity } \\
\text { (NRS) }\end{array}$ & 25 & 15 & $7.0 \pm 1.7$ & $5.1 \pm 1.8$ \\
$\begin{array}{c}\text { Pain-related suffering } \\
\text { (NRS) }\end{array}$ & $6.3 \pm 1.9$ & $6.2 \pm 2.0$ & $7.7 \pm 1.6$ & $4.8 \pm 1.1$ \\
$\begin{array}{c}\text { Pain duration } \\
\text { (months) }\end{array}$ & $11.7 \pm 30.6$ & $6.0 \pm 2.5$ & $21.0 \pm 39.4$ & $28.5 \pm 51.7$ \\
Satisfaction (VAS) & $41.4 \pm 18.0$ & $2.7 \pm 2.4$ & $34.2 \pm 16.6$ & $54.1 \pm 7.3$ \\
\hline
\end{tabular}

mean $\pm \mathrm{SD}$

Table 2. Pain intensity, pain-related suffering and patient satisfaction level before and after treatment.

\begin{tabular}{|c|c|c|c|c|c|}
\hline & $\begin{array}{c}\text { Before } \\
\text { treatment }\end{array}$ & $\begin{array}{c}\text { After } \\
\text { treatment }\end{array}$ & $\begin{array}{c}\text { Rate of } \\
\text { improvement }\end{array}$ & $\begin{array}{c}\text { Difference } \\
(95 \% \mathrm{CI})\end{array}$ & $\mathrm{p}$ value \\
\hline $\begin{array}{l}\text { Pain intensity } \\
\text { (NRS) }\end{array}$ & $6.3 \pm 1.9$ & $4.3 \pm 1.8$ & $0.27 \pm 0.34$ & $\begin{array}{c}2.0 \\
(1.3 \text { to } 2.7)\end{array}$ & $\mathrm{p}<0.001$ \\
\hline $\begin{array}{c}\text { Pain-related } \\
\text { suffering } \\
\text { (NRS) }\end{array}$ & $6.3 \pm 2.4$ & $3.8 \pm 2.1$ & $0.36 \pm 0.35$ & $\begin{array}{c}2.5 \\
(1.8 \text { to } 3.2)\end{array}$ & $\mathrm{p}<0.001$ \\
\hline $\begin{array}{l}\text { Satisfaction } \\
\text { (VAS) }\end{array}$ & $41.4 \pm 18.0$ & $63.9 \pm 15.8$ & $-1.02 \pm 1.76$ & $\begin{array}{c}122.5 \\
(-29.1 \text { to }-15.8)\end{array}$ & $\mathrm{p}<0.001$ \\
\hline
\end{tabular}

mean \pm SD. 95\%CI: 95\% confidence interval

\section{RESULTS}

Between February 2011 and March 2012, a total of 44 participants were recruited; their characteristics are summarized in Table 1. Musculoskeletal disorders were distributed as follows: 25 patients $(56.8 \%)$ with shoulder pain; 13 patients $(29.5 \%)$ with low back pain; and 6 patients $(13.6 \%)$ with knee osteoarthritis. Twenty-five participants $(56.8 \%)$ were women, the mean \pm SD age was $64.0 \pm 10.9$ years, and the mean \pm SD pain duration was $11.6 \pm 30.6$ months. Pre- and post-measurement scores for pain intensity, pain-related suffering, and the patient satisfaction level are shown in Table 2. Although no significant differences in pain intensity and pain-related suffering before treatment were found (pain intensity, $6.3 \pm 1.9$; pain-related suffering, $6.3 \pm 2.4$; Difference, -0.03 ; $95 \% \mathrm{CI},-0.49$ to 0.42 ), significant difference was observed in pain intensity and pain-related suffering after treatment (pain intensity, $4.3 \pm 1.8$; pain-related suffering, $3.8 \pm 2.1$; Difference, 0.46 ; $95 \% \mathrm{CI}, 0.05$ to 0.87). Significant improvements in pain intensity, pain-related suffering, and the patient satisfaction level after treatment compared with before treatment. The rate of improvement in pain-related suffering was significantly higher than that in pain intensity (pain intensity, $0.27 \pm 0.34$; pain-related suffering, $0.36 \pm$ 0.35 ; Difference, -0.09 ; $95 \% \mathrm{CI},-0.16$ to -0.02 ) Significant difference was observed in the proportion of Zero, Plus, and Minus before and after treatment ( $\mathrm{p}$ $<0.01$ ) (Table 3). Multiple linear regression analysis showed that only pain intensity before treatment was related to the patient satisfaction level before treatment and only the rate of improvement in pain-related suffering was related to the patient satisfaction level after treatment (Table 4). 
Table 3. The proportion of Zero, Plus, and Minus before and after treatment.

\begin{tabular}{cccc} 
& $\begin{array}{c}\text { Zero } \\
\text { (Intensity = Suffering) }\end{array}$ & $\begin{array}{c}\text { Plus } \\
\text { (Intensity > Suffering) }\end{array}$ & $\begin{array}{c}\text { Minus } \\
\text { (Intensity < Suffering) }\end{array}$ \\
\hline $\begin{array}{c}\text { Before } \\
\text { treatment } \\
\begin{array}{c}\text { After } \\
\text { treatment }\end{array}\end{array}$ & $24(54.5)^{* * *}$ & $9(20.5)^{* * *}$ & $11(25)$ \\
\hline
\end{tabular}

$\mathrm{n}(\%)$. Chi-square $=11.847 ; \mathrm{p}=0.003 .{ }^{* *}$ Adjusted residual analysis: $\mathrm{p}<0.01$

Table 4. Multiple linear regression analyses for patient satisfaction level before and after treatment as the dependent variable and age, pain duration, pain intensity, pain-related suffering before and after treatment, and the rate of improvement in pain intensity and pain-related suffering as independent variables.

\begin{tabular}{|c|c|c|c|c|}
\hline Dependent variable & Independent variables & Standardized B & Adjusted $\mathrm{R}^{2}$ & $\mathrm{p}$ value \\
\hline $\begin{array}{c}\text { Satisfaction } \\
\text { before treatment }\end{array}$ & $\begin{array}{c}\text { Pain intensity before } \\
\text { treatment }\end{array}$ & -0.50 & 0.24 & $p<0.001$ \\
\hline $\begin{array}{c}\text { Satisfaction } \\
\text { after treatment }\end{array}$ & $\begin{array}{l}\text { Rate of improvement in } \\
\text { pain-related suffering }\end{array}$ & 0.48 & 0.21 & $\mathrm{p}<0.001$ \\
\hline
\end{tabular}

\section{DISCUSSION}

Although no significant difference was observed between pain intensity and pain-related suffering before treatment in our study, a significant difference was observed between pain intensity and pain-related suffering after treatment, and the rate of improvement in pain-related suffering was higher than that in pain intensity. These results might indicate that NRS of pain-related suffering designed to measure pain affect distinct from measures of pain intensity. The assessment of pain-related suffering using NRS is a very attractive tool for measuring pain-related suffering (consisting of disability and a negative response to pain-related fear, anxiety, depression, and isolation) in the clinical setting because of its simplicity and relative ease of use. Both average NRS of pain intensity and pain-related suffering changed by over two points from before treatment to after treatment. Treatment in this study was effective because a two-point change on NRS of pain intensity represents a clinically meaningful change ${ }^{21,22)}$. The main treatment used in this study was exercise therapy accompanied by patient education. Systematic review points to exercise having a small-to-moderate beneficial effect on pain intensity and function in disorders such as shoulder pain, low back pain, knee osteoarthritis, and fibromyalgia ${ }^{23)}$. Similarly, pain neuroscience education has a positive effect on pain intensity, disability, and catastrophization in patients with musculoskeletal disorders ${ }^{24)}$. Therefore, in this study, these treatments are likely to be effective in reducing pain intensity. We found that the rate of improvement in pain-related suffering was significantly higher than that in pain intensity. The results of the chi-square test also indicated that pain intensity and pain-related suffering were at the same grade before treatment but that pain-related suffering decreased after treatment. Many patients reported that the pain-related suffering was cause by disability or negative beliefs about pain. Physical role limitation was related to suffering evaluated using Pain Discomfort Scale ${ }^{25)}$. Negative beliefs about low back pain are associated with high pain intensity and high-level disability in community-based women ${ }^{26)}$. Fear-avoidance beliefs are a type of negative pain beliefs. Increased fear-avoidance beliefs have a negative impact on low back pain outcomes as they delay recovery and heighten disability ${ }^{27)}$. Exercise therapy is useful in changing the course of disability and fear-avoidance beliefs in patients with musculoskeletal disorders ${ }^{28,}{ }^{29}$. Although there is insufficient evidence, we speculated that that exercise therapy and education might be more effective in pain-related suffering than in pain intensity.

The interesting finding of this study was that the primary factor for patient satisfaction changed from pain intensity before treatment to the rate of improvement in pain-related suffering. The average VAS of patient satisfaction changed by over 20 from before treatment to after treatment; the minimal clinically significant difference in patient satisfaction was $7-11^{13)}$. From this viewpoint, the power of this study is sufficient for determining the association 
between each patient's pain intensity, pain-related suffering, and patient satisfaction level. It is debatable whether there is an association between pain intensity and the patient satisfaction level. Although some studies reported that pain intensity was associated the patient satisfaction level ${ }^{17-19)}$, some studies reported that that pain intensity was not associated the patient satisfaction level ${ }^{16,20)}$. This difference may result from a difference in the sources of pain and the clinical setting. Stahmer et al. ${ }^{17)}$ proposed that pain relief alone is not the only factor that affects the patient satisfaction level, although this satisfaction level was associated with the amount of pain relief achieved by linear relationship analysis. However, in their work, Stahmer et al did not measure pain-related suffering. In the present study, the patient satisfaction level after treatment was related more to the rate of improvement in pain-related suffering than to pain intensity, when the rate of improvement in pain intensity and pain-related suffering were used as independent variables simultaneously. Pain-related suffering seems to encompass more than emotional functioning and physical functioning. Therefore, patient satisfaction level and pain-related suffering might be considered similar concepts, and therefore, the rate of improvement in pain-related suffering is more associated with the patient satisfaction level after treatment. These results give important information that would allow clinicians to determine a treatment policy. Clinicians ask patients detailed questions about their pain-related suffering before treatment. The patients' answers are considered when determining the appropriate medical treatment to be given, thus allowing patient satisfaction to improve.

Several limitations of our study should be considered. First, as this study was conducted in a clinical setting, there were a small number of participants. Therefore, we can commit Type I error and Type II error. However, $p$ value in the paired $t$ test and the multiple linear regression were less than 0.001 and powers generated by power analysis in the paired $t$ test and the multiple linear regression analysis were more than 0.90 . For this result, there was little possibility of Type I error and Type II error and the sample size seems to be sufficient in this study. Second, a lack of a treatment group including patients undergoing intra-articular or muscle trigger point injection, nerve block, or medication other than NSAIDs. A second study with a control group will be needed to arrive at a definite conclusion. Third, the measurement of pain-related suffering using NRS has not been validated in previous studies. VAS is difficult to discriminate a little difference between pain intensity and pain-related suffering. For example, it is unclear 3 $\mathrm{mm}$ difference between pain intensity and pain-related difference is meaningful difference. Therefore, we used NRS to evaluate clearly whether pain intensity and pain-related is the difference or same. Future study confirming the usefulness of this measurement and validating it against other measures of pain-related suffering would be valuable for confirming the present results. Fourth, treatment in this study was for a short period, and it is known that there is an association between pain intensity, pain-related suffering, and the patient satisfaction level with long-term treatment. However, we believe that the treatment period in this study was sufficient and that the outcome would not change even if the treatment period was lengthened because the difference between before and after treatment in patient satisfaction was greater than the minimal clinically significant difference in patient satisfaction. Fifth, our study includes various types of musculoskeletal disorder and pain duration. These may impact on the results of this study.

In conclusion, the present findings suggest that the primary factor for patient satisfaction changes from pain intensity before treatment to the rate of improvement in pain-related suffering. We believe that treatment based on consideration of pain-related suffering could be effective in improving satisfaction.

\section{REFERENCES}

1) Croft P, Rigby AS, Boswell R, et al: The prevalence of chronic widespread pain in the general population. J Rheumatol 20: 710-713, 1993.

2) Bergman $S$, Herrström $P$, Högström $K$, et al: Chronic musculoskeletal pain, prevalence rates, and sociodemographic associations in a Swedish 
population study. J Rheumatol 28: 1369-1377, 2001.

3) Wijnhoven HA, de Vet HC, Picavet HS: Prevalence of musculoskeletal disorders is systematically higher in women than in men.

Clin J Pain 22: 717-724, 2006.

4) Picavet HS, Schouten JS: Musculoskeletal pain in the Netherlands: prevalences, consequences and risk groups, the DMC(3)-study. Pain 102: 167-178, 2003.

5) Chapman CR, Gavrin J: Suffering: the contributions of persistent pain. Lancet 353: 2233-2237, 1999.

6) Turk DC, Wilson HD: Pain, suffering, pain-related suffering--are these constructs inextricably linked? Clin J Pain 25: 353-355, 2009.

7) Loeser JD: Pain and suffering. Clin J Pain 16: S2-6, 2000.

8) Cassell EJ: The nature of suffering and the goals of medicine. N Engl J Med 306: 639-645, 1982.

9) Kahn DL, Steeves RH: The experience of suffering: conceptual clarification and theoretical definition. J Adv Nurs 11: 623-631, 1986.

10) Chapman CR, Gavrin J: Suffering and its relation to pain. J Palliat Care 9: 5-13, 1993.

11) Gracely RH, McGrath F, Dubner R: Ratio scales of sensory and affective verbal pain descriptors.

Pain 5: 5-18, 1978.

12) Jensen MP, Karoly P, Harris P: Assessing the affective component of chronic pain: development of the Pain Discomfort Scale. J Psychosom Res 35: 149-154, 1991.

13) Singer AJ, Thode HC Jr.: Determination of the minimal clinically significant difference on a patient visual analog satisfaction scale. Acad Emerg Med 5: 1007-1011, 1998.

14) Brokelman RB, van Loon CJ, Rijnberg WJ: Patient versus surgeon satisfaction after total hip arthroplasty. J Bone Joint Surg Br 85: 495-498, 2003.

15) Fugl-Meyer AR, Melin R, Fugl-Meyer KS: Life satisfaction in 18- to 64-year-old Swedes: in relation to gender, age, partner and immigrant status. J Rehabil Med 34: 239-246, 2002.

16) Stålnacke BM: Life satisfaction in patients with chronic pain - relation to pain intensity, disability, and psychological factors. Neuropsychiatr Dis Treat 7: 683-689, 2011.

17) Stahmer SA, Shofer FS, Marino A, et al: Do quantitative changes in pain intensity correlate with pain relief and satisfaction? Acad Emerg Med 5: 851-857, 1998.

18) Müller-Staub M, Meer R, Briner G, et al: Measuring patient satisfaction in an emergency unit of a Swiss university hospital: occurrence of anxiety, insecurity, worry, pain, dyspnoea, nausea, thirst and hunger, and their correlation with patient satisfaction (part 2). Pflege 21: 180-188, 2008.

19) McNeill JA, Sherwood GD, Starck PL, et al: Pain management outcomes for hospitalized Hispanic patients. Pain Manag Nurs 2: 25-36, 2001.

20) Phillips $S$, Gift $M$, Gelot $S$, et al: Assessing the relationship between the level of pain control and patient satisfaction. J Pain Res 6: 683-689, 2013.

21) Childs JD, Piva SR, Fritz JM: Responsiveness of the numeric pain rating scale in patients with low back pain. Spine (Phila Pa 1976) 30: 1331-1334, 2005.

22) Cleland JA, Childs JD, Whitman JM: Psychometric properties of the Neck Disability Index and Numeric Pain Rating Scale in patients with mechanical neck pain. Arch Phys Med Rehabil 89: 69-74, 2008.

23) Hagen KB, Dagfinrud H, Moe RH, et al: Exercise therapy for bone and muscle health: an overview of systematic reviews. BMC Med 10: 167, 2012.

24) Louw A, Diener I, Butler DS, et al: The effect of neuroscience education on pain, disability, anxiety, and stress in chronic musculoskeletal pain. Arch Phys Med Rehabil 92: 2041-2056, 2011.

25) Lackner JM, Jaccard J, Blanchard EB: Testing the sequential model of pain processing in irritable bowel syndrome: a structural equation 
modeling analysis. Eur J Pain 9: 207-218, 2005.

26) Urquhart DM, Bell RJ, Cicuttini FM, et al:

Negative beliefs about low back pain are

associated with high pain intensity and high

level disability in community-based women.

BMC Musculoskelet Disord 9: 148, 2008.

27) Rainville J, Smeets RJ, Bendix T, et al:

Fear-avoidance beliefs and pain avoidance in low back pain--translating research into clinical practice. Spine J 11: 895-903, 2011.

28) Marshall PW, Kennedy S, Brooks C, et al:

Pilates exercise or stationary cycling for chronic nonspecific low back pain: does it matter? a randomized controlled trial with 6-month follow-up. Spine (Phila Pa 1976) 38: E952-E959, 2013.

29) Monticone M, Ferrante S, Rocca B, et al: Home-based functional exercises aimed at managing kinesiophobia contribute to improving disability and quality of life of patients undergoing total knee arthroplasty: a randomized controlled trial. Arch Phys Med Rehabil 94: 231-239, 2013. 